\title{
BALANÇO HÍDRICO CLIMATOLÓGICO 1961-1990 E INDICE DE ANOMALIA DE CHUVAS (IAC) APLICADO AO PERÍODO DE 2011, 2012 E 2013 PARA COMPREENSÃO DA SECA DE 2014 NO MUNICÍPIO DE PARANAÍBA/MS
}

\author{
Denivaldo Ferreira de Souza ${ }^{1}$
}

\begin{abstract}
RESUMO
Neste trabalho procurou-se estabelecer o balanço hídrico climático a partir das normais climatológicas de 19611990 apresentadas pelo INMET e calcular o índice de anomalia de chuvas (IAC) proposto por Rooy (1965) para os períodos de 2011, 2012 e 2013 mensalmente para o município de Paranaíba, localizado no nordeste do Estado de Mato Grosso do Sul. O município possui um clima tropical, tendo a fórmula climática segundo classificação Köppen em Aw, sendo caracterizado com um verão chuvoso e inverno seco. As médias anuais da precipitação apresentadas nas normais foram $1455 \mathrm{~mm}$ /ano e temperaturas $23^{\circ} \mathrm{C} / \mathrm{ano}$. A aplicação do IAC foi propicia para a compreensão da seca atual em 2014, mostrando que o resultado é o acumulo de anos com baixas precipitações que ocasionaram a situação de seca que vive o município de Paranaíba.
\end{abstract}

PALAVRAS-CHAVE: Balanço Hídrico; Índice de Anomalia de Chuvas; IAC; Paranaíba.

\section{1-1990 CLIMATOLOGICAL WATER BALANCE AND RAINFALL ANOMALY INDEX (RAI) APPLIED TO THE PERIOD OF 2011, 2012 AND 2013 TO UNDERSTAND THE DROUGHT OF 2014 IN THE CITY OF PARANAÍBA/MS}

\begin{abstract}
In this study we sought to establish the water balance from climatological normals for 1961-1990 presented by INMET and calculate the rainfall anomaly index (RAI) proposed by Rooy (1965) for the periods 2011, 2012 and 2013 for monthly the municipality of Paranaiba, located in the northeast of the state of Mato Grosso do Sul. The municipality has a tropical climate, having the second formula Koppen climate classification Aw, being featured with a rainy summer and dry winter. The average annual rainfall of $1455 \mathrm{~mm} /$ year were presented in the normal and temperatures $23^{\circ} \mathrm{C} /$ year. The application provides the RAl was to understand the current drought in 2014,
\end{abstract}

\footnotetext{
${ }^{1}$ Geógrafo, mestrando em Geografia pela Universidade Federal de Mato Grosso do Sul/UFMS, campus de Três Lagoas. E-mail deny1609@gmail.com
} 

municipality of Paranaiba.

\section{1-1990 BALANCE HIDRICO CLIMATOLOGICA E TASA DE LLUVIA ANOMALÍAS (TLA) APLICADA AL PERIODO DE 2011, 2012 Y 2013 PARA ENTENDER LA SEQUÍA DE 2014 EN LA CIUDAD DE PARANAÍBA/MS}

\section{RESUMEN}

En este estudio hemos tratado de establecer el balance hídrico de las normales climatológicas para 1961-1990 presentado por INMET y calcular la tasa de precipitaciones anomalía (TLA), propuesto por Rooy (1965) para los períodos 2011, 2012 y 2013 para mensual el municipio de Paranaíba, situado en el noreste del estado de Mato Grosso do Sul. municipio tiene un clima tropical, que tiene la segunda fórmula de clasificación de Koppen el clima

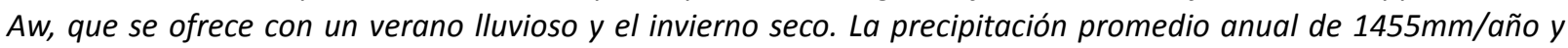

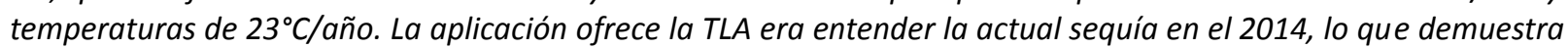
que el resultado es la acumulación de años con escasas precipitaciones que causaron la sequía experimentada por el municipio de Paranaíba.

PALABRAS-CLAVE: Balande Hidrico; Tasa de Lluvia Anomalías; TLA; Paranaíba.

\section{INTRODUÇÃO}

A definição de um clima é definido em termos dos valores das variáveis climáticas, e as principais são a temperatura e a precipitação. As suas anomalias causam grandes impactos à sociedade, à economia e ao meio ambiente, e estes podem variar desde secas até enchentes. Deste modo, para Madruga et. al. (1999) a previsão destas anomalias pode auxiliar a sociedade a prevenir-se contra possíveis danos. Devido à possibilidade da temperatura do ar e a precipitação estarem relacionadas a outras variáveis, e suas variações alterarem as atividades humanas, muitos pesquisadores têm investigado a sua previsibilidade e suas variações.

A previsão e o monitoramento de períodos secos ou períodos chuvosos são particularmente úteis devido aos seguintes aspectos: $O$ abastecimento de água das cidades, em sua maioria, é dependente diretamente do escoamento dos rios, ou indiretamento do volume acumulado nas barragens; A maioria das culturas agrícolas 
Volume 10, Número 2, 2014

Bacias Hidrográficas, Planejamento e Gestão dos Recursos Hídricos

depende exclusivamente da regularidade das chuvas e; A possibilidade de uso da água subterrânea é pequena comparada ao da água superficial (FREITAS, 2004 apud ARAÚJO et. al., 2009)

Sansigolo (2004) citando Dracup et al.(1980), e Olapido,(1985) exemplifica quatro definições de seca baseadas em considerações meteorológicas, hidrológicas, agrícolas, e econômicas: seca meteorológica, refere-se a precipitação abaixo das normais esperadas; secas hidrológicas e agrícolas, referem-se respectivamente, a níveis de rios e reservatórios abaixo do normal e a umidade do solo insuficiente para suprir a demanda das plantas; e a seca econômica, a qual ocorre quando o déficit de água induz a falta de bens ou serviços (energia elétrica, alimentos e etc) devido ao volume inadequado, a má distribuição das chuvas, ao aumento no consumo, ou ainda ao mau gerenciamento dos recursos hídricos.

Deste modo, o monitoramento desses períodos pode ser efetuado através do emprego de índices. Com base neles, pode-se desenvolver um sistema de acompanhamento das características dos períodos secos ou chuvosos, assim como as diferenciadas medidas a serem efetivadas de acordo com os valores atingidos por tais parâmetros.

O Índice de Anomalia de Chuvas (IAC) praticado em pesquisas científicas propicia resultados significativos e segundo Repelli et. al. (1998), o IAC parece ser apropriado para utilização em regiões semi-áridas e tropicais. A facilidade de acesso aos dados de precipitação mensais em tempo real é um fator importante e faz do índice uma ferramenta potencial para aplicações de monitoramento durante a estação chuvosa.

\section{ÁREA DE ESTUDO}

O município de Paranaíba está situado no nordeste do estado de Mato Grosso do Sul. Fundada em 1838, Paranaíba teve importante papel na Guerra do Paraguai, pois foi rota de apoio logístico para a fuga dos civis envolvidos nesse conflito. Tem 
forte apoio para a pecuária nacional e está entre as cidades mais importantes do estado.

A localização geográfica está inserida nas coordenadas de latitude 1907'19" a $19^{\circ} 58^{\prime} 10^{\prime \prime}$ sul e longitude $50^{\circ} 55^{\prime} 31^{\prime \prime}$ a 5151'15' oeste (Figura 1). Possui população estimada pelo IBGE (2014) em 41.363 mil habitantes. Está sob influência do clima tropical classificado por Köppen em AW, com verão quente e chuvoso e inverno "frio" e seco. A temperatura média anual é de $23^{\circ} \mathrm{C}$, com precipitação pluviométrica anual de $1.455 \mathrm{~mm}$.

Figura 1: Mapa de Localização do município de Paranaíba/MS.

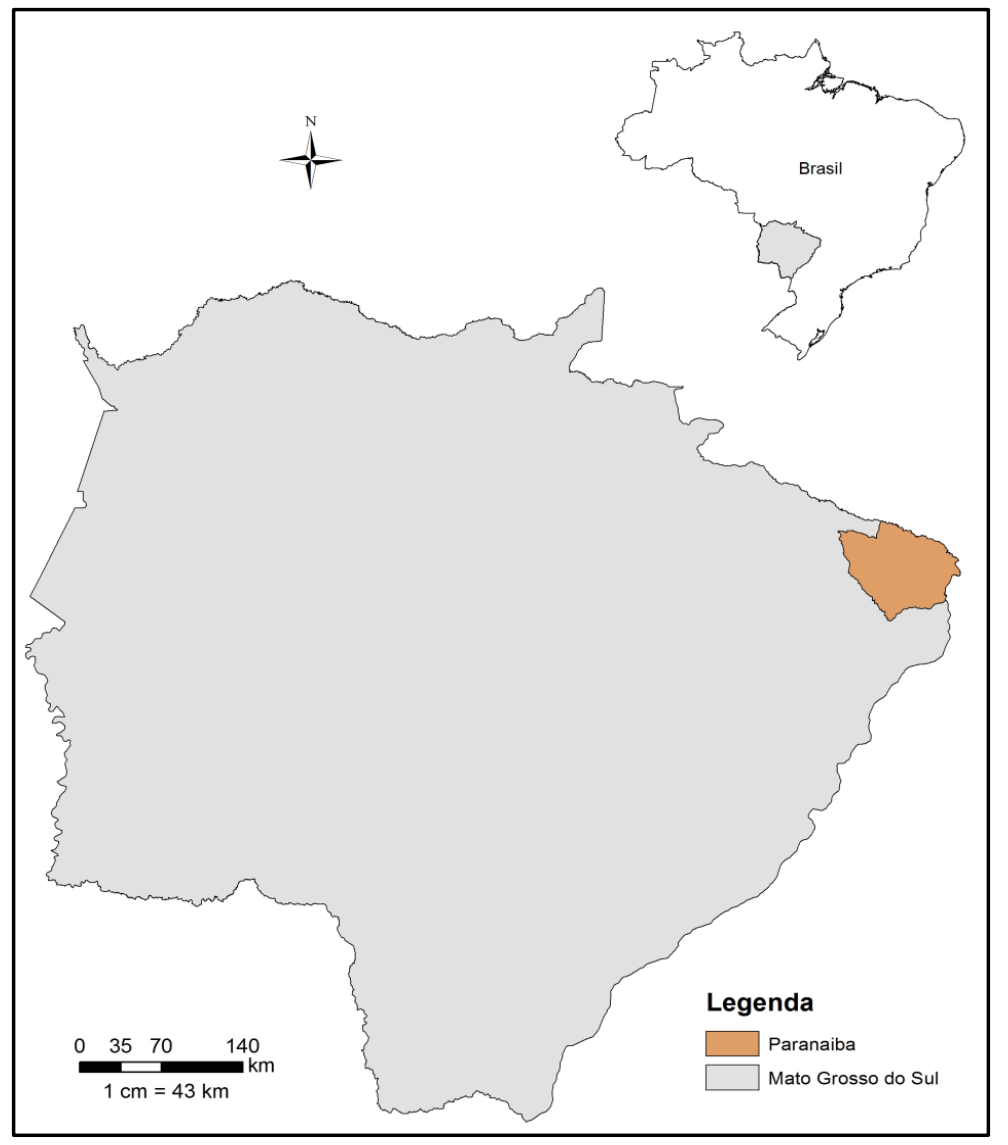

\section{METODOLOGIA}

Usou-se a elaboração de um climograma como ferramenta clássica de representação do clima que permite uma compreensão mais fácil do perfil climático de 
determinada região. E, através do mesmo pode se representar graficamente as variações de temperatura e precipitações durante um determinado período de tempo.

Para sua construção sob a forma gráfica, foram colocados no eixo das abscissas ( $\mathrm{x}$ ) em forma de coluna as médias mensais de precipitação, em milímetros $(\mathrm{mm})$, e no eixo das ordenadas (y) em forma de linhas as médias, máximas e mínimas mensais da temperatura $\left({ }^{\circ} \mathrm{C}\right)$, ambos os dados contidos nas normais climatológicas de 1961-1990 do INMET (1992). Na base do gráfico foram colocados os 12 meses do ano, e unindo-se os 12 pontos referentes a cada mês aos respectivos índices de chuva e a temperatura, podendo ser visualizadas as variações mensais pluviométricas e da temperatura de cada mês, bem como suas correlações.

O Índice de Anomalia de Chuva (IAC), em sua geração necessita de dados de precipitação, é simples de ser calculado e visa tornar o desvio da precipitação em relação à condição normal de diversas regiões passíveis de comparação. Considerado mais coerente, será usado o Rainfall Anomaly Index (RAI) ou Índice de Anomalia de Chuva (IAC) desenvolvido e utilizado por Rooy (1965) e detalhado sucintamente por Araújo et. al. (2009).

$$
\begin{gathered}
I A C=3\left[\frac{(N-\bar{N})}{(\bar{M}-\bar{N})}\right] ; \text { para anomalias positivas } \\
I A C=-3\left[\frac{(N-\bar{N})}{(\bar{X}-\bar{N})}\right] ; \text { para anomalias negativas }
\end{gathered}
$$

Em que $\mathrm{N}$ é a precipitação mensal atual, ou seja, do mês que será gerado o IAC $(\mathrm{mm}) ; \overline{\mathrm{N}}$ é a precipitação média mensal da série histórica $(\mathrm{mm}) ; \overline{\mathrm{M}}$ é a média das dez maiores precipitações mensais da série histórica $(\mathrm{mm}) ; \overline{\mathrm{X}}$ é a média das dez menores precipitações mensais da série histórica $(\mathrm{mm})$; e as anomalias positivas são valores acima da média e as negativas, abaixo da média.

A partir da metodologia de Rooy (1965) foi calculado o IAC através das normais fornecidas pelo INMET (1992) para caracterizar mensalmente os anos de 2011, 2012 
e 2013 obtidos na AGRAER (2014), classificando-os em meses secos ou chuvosos, e posteriormente, os anos conforme Quadro 1.

Quadro 1: Faixa de valores do IAC com suas respectivas classes de intensidade.

\begin{tabular}{|c|c|c|}
\hline \multirow{4}{*}{ Índice de Anomalia de Chuva } & Faixa do IAC & Classe de Intensidade \\
\cline { 2 - 3 } (IAC) & Acima de 4 & Extremamente Úmido \\
& 2 a 4 & Muito Úmido \\
0 a 2 & Úmido \\
0 a -2 & Seco \\
& -2 a -4 & Muito Seco \\
& Abaixo de -4 & Extremamente Seco \\
\hline
\end{tabular}

Fonte: Araújo et. al. (2009).

Utilizando, por fim, do software Microsoft Excel 2010 para a criação dos gráficos representativos de forma didática, possibilitando a melhor compreensão de peritos e leigos na área.

\section{RESULTADOS}

Os dados propiciaram a construção de um climograma que podem ser definido em um climograma tropical, sendo as maiores temperaturas e chuvas ocorridas no verão e os menores índices pluviométricos e temperaturas ocorridos no inverno.

As precipitações mais altas, no período de 30 anos, são encontradas em janeiro e dezembro com valores acima de $260 \mathrm{~mm}$, coincidindo com o verão. As menores precipitações estão nos meses de agosto e julho com valores abaixo de $40 \mathrm{~mm}$, estação de inverno.

As temperaturas apresentaram-se em três divisões, caracterizando bem o gradiente térmico do tropicalismo. A média em 30 anos ficou em $23^{\circ} \mathrm{C}$, a máxima absoluta teve destaque em setembro que chegou atingir valor acima de $40^{\circ} \mathrm{C}$, e por fim, a mínima absoluta dos meses de julho e agosto marcaram os menores valores chegando na faixa de $1^{\circ} \mathrm{C}$ (Figura 2). 
Figura 2: Climograma representativo das normais climatológicas de 1961-1990 do município de Paranaíba/MS.

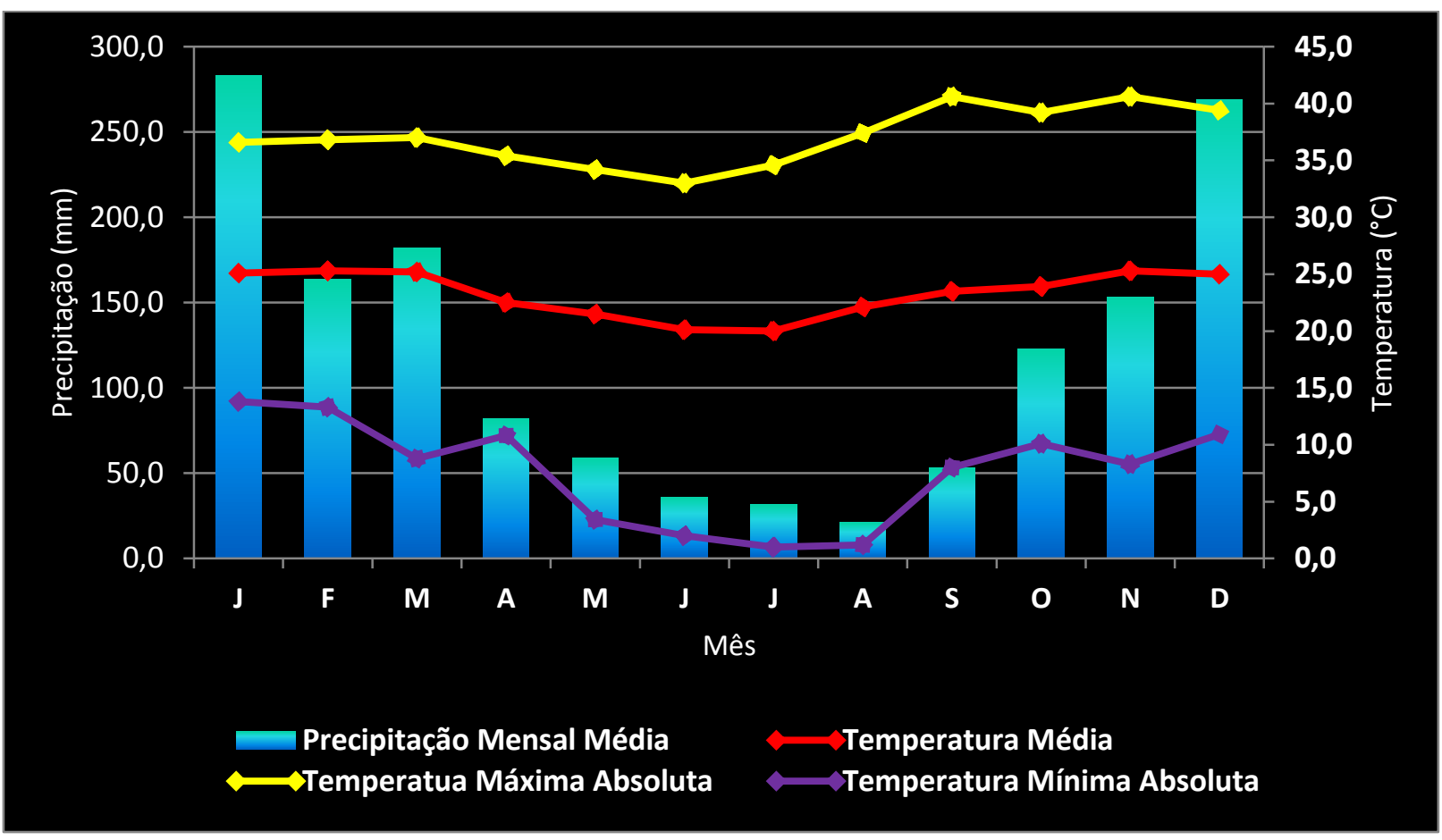

Uma comparação média das normais de 1961-1990 e os anos de 2011, 2012 e 2013 evidencia o real déficit hídrico que instalou em 2014. Em quase todos os meses as média das normais foram maiores que os anos da pesquisa (Figura 3).

Figura 3: Gráfico comparativo da precipitação mensal média das normais de 1961-1990 e dos anos de 2011, 2012 e 2013. 


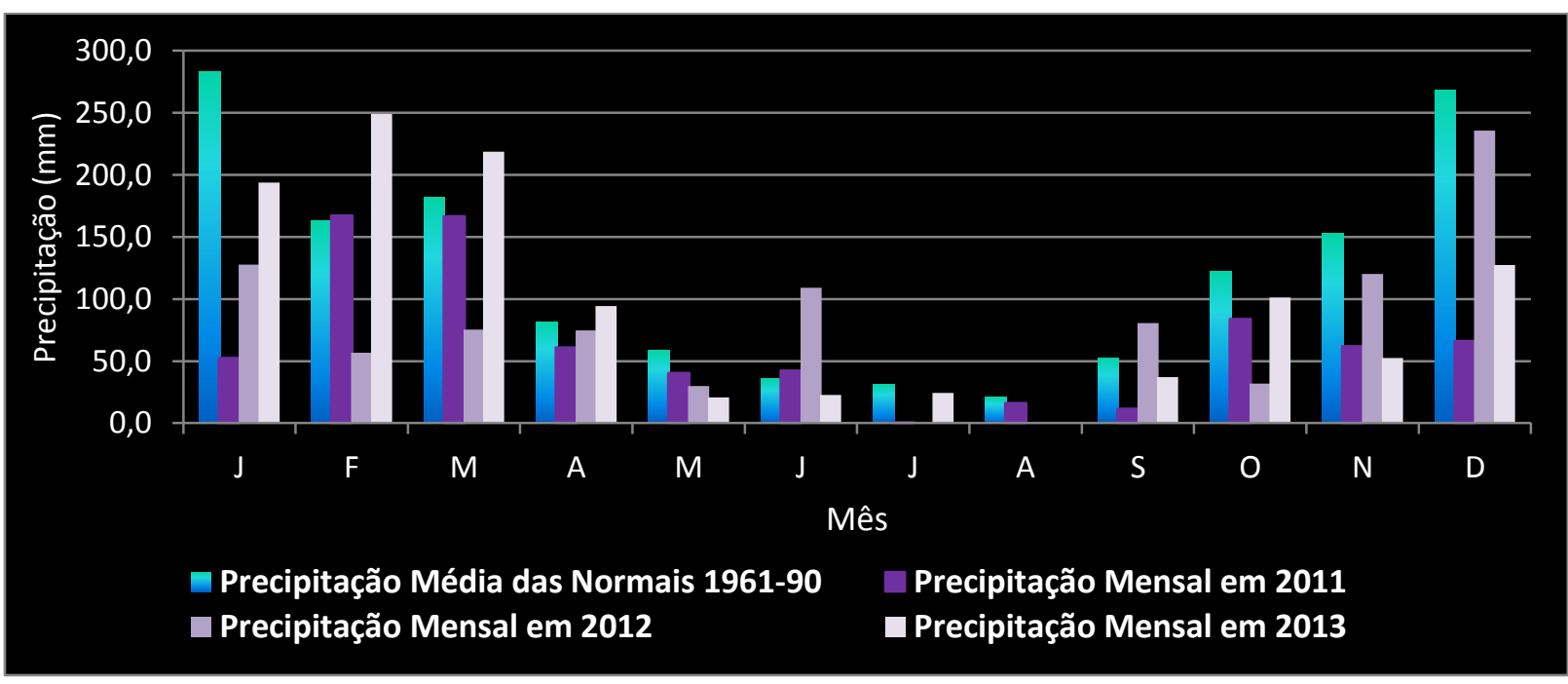

A Figura 4 indica o IAC mensal em 2011, tendo janeiro como um mês extremamente seco; Outros 4 meses enquadraram-se em períodos muito secos; E apenas junho teve úmido de destaque. De uma maneira geral 2011 foi classificado em um ano muito seco.

Figura 4: Índice de Anomalia de Chuva mensal em 2011.

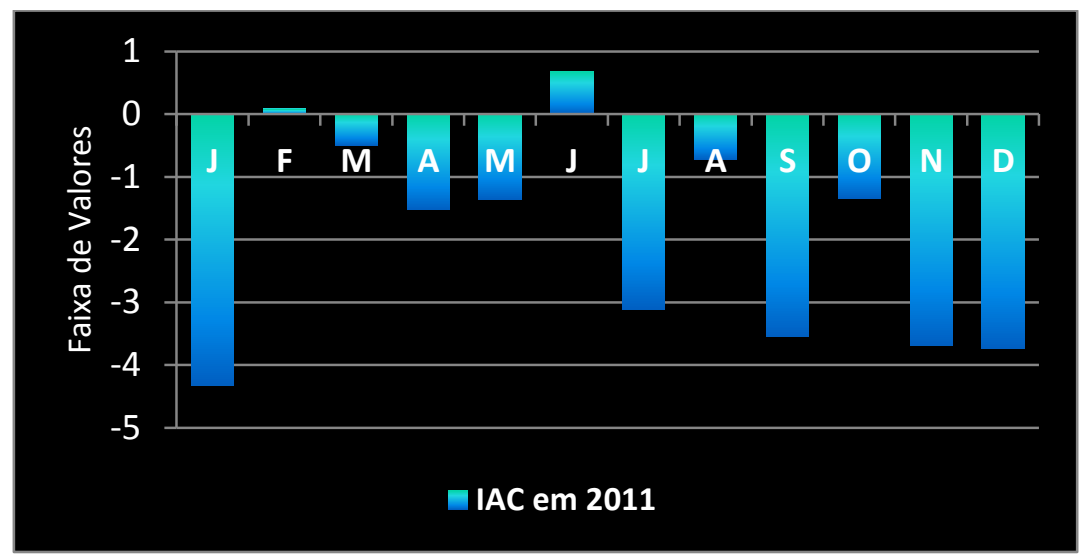

O IAC mensal em 2012, Figura 5, teve 7 meses enquadraram-se em períodos muito secos; $E$ apenas julho como mês extremamente úmido para suprir a falta de chuva. Contudo, o ano de 2012 igual a 2011 foi classificado também em um ano muito seco. 
Figura 5: Índice de Anomalia de Chuva mensal em 2012.

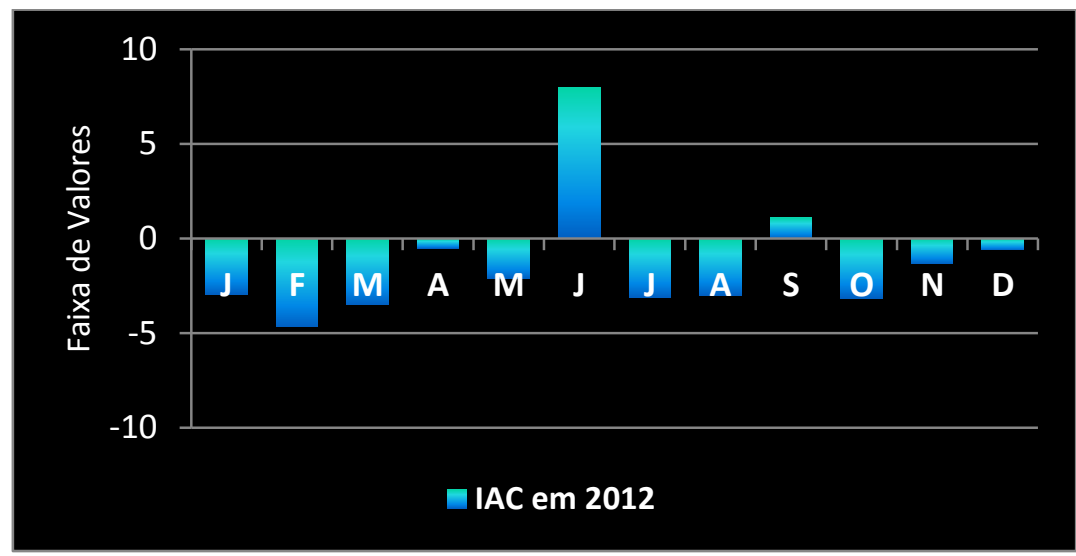

A Figura 6 ilustra o IAC mensal em 2013, tendo novembro como um mês extremamente seco; Outros 8 meses enquadraram-se em períodos muito secos; E apenas 3 meses tiveram período úmido. O ano de 2013 também entrou na classificação de ano muito seco.

Figura 6: Índice de Anomalia de Chuva mensal em 2013.

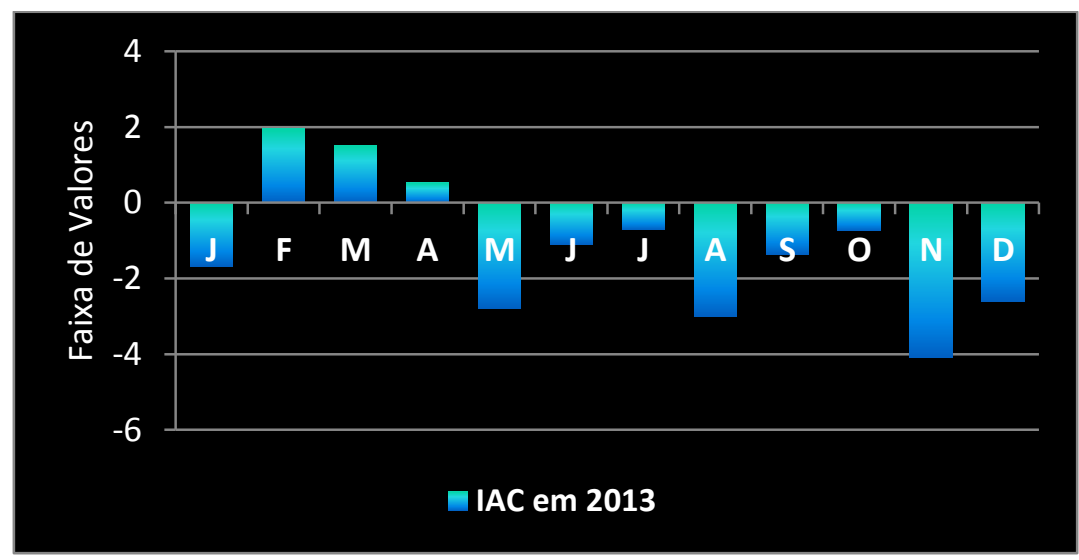

A partir do IAC dos 3 anos fez-se a variação de faixa de valores mensais de todo o período. Assim ficou caracterizado o predomínio de seca durante 2011 à 2013 no município de Paranaíba, que dentre os 36 meses teve apenas 6 enquadrados em úmido, muito úmido ou extremamente úmido. 
Figura 7: Variação do Índice de Anomalia de Chuva mensal para o período de Janeiro de 2011 a Dezembro de 2013.

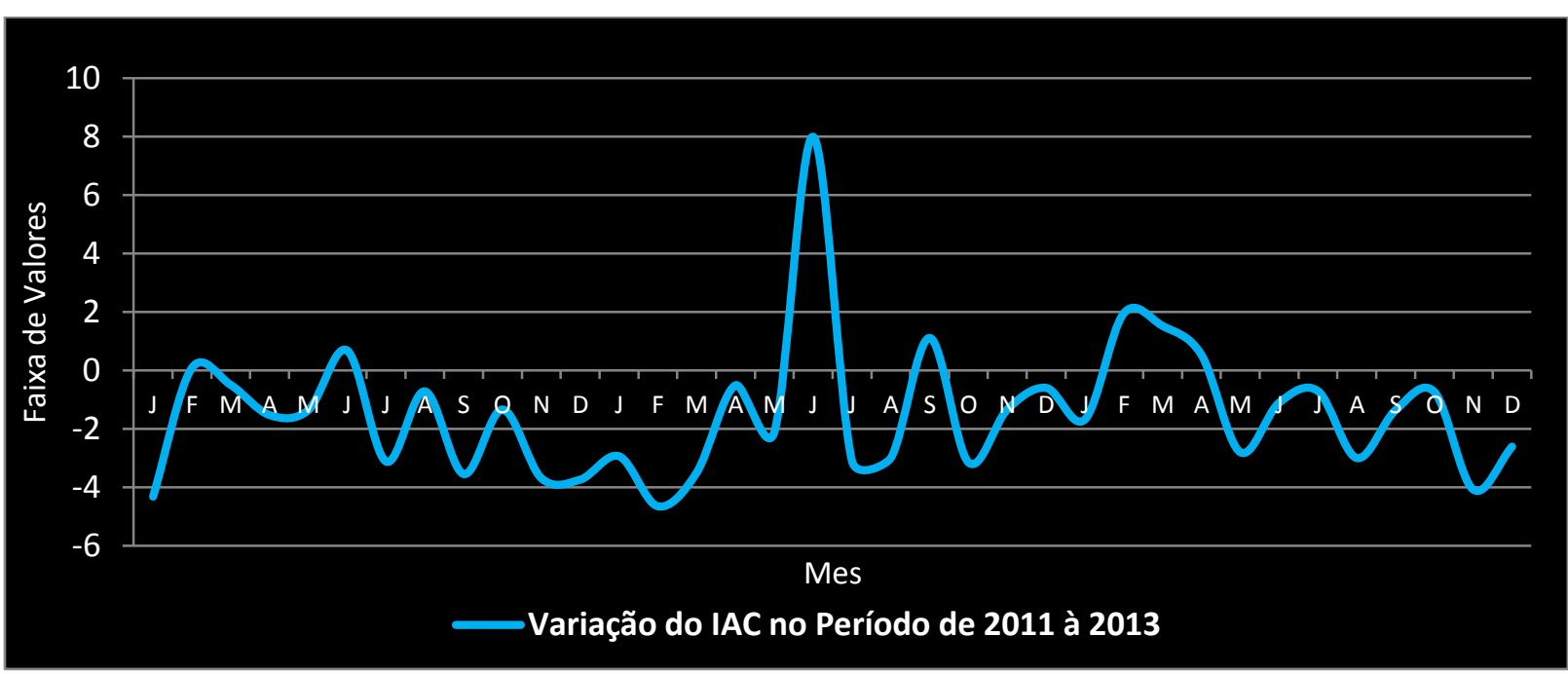

\section{CONCLUSÃO}

O período dos anos 2011, 2012 e 2013 ficaram caracterizados pelo IAC como secos em relação às normais de 1961-1990. Esse resultado mostra que a seca histórica de 2014 presente no município de Paranaíba (seca também presente no Sul e Sudeste do Brasil) pode ser explicada pelo acumulo de déficit hídrico pluvial ano após ano e chegando ao patamar drástico atual.

Para Santos (1998) as consequências das secas podem ser diretas e indiretas: entre as consequências diretas (Figura 8) destacam-se a falta do fornecimento de água para abastecimento urbano, os prejuízos na agricultura, na indústria e na produção de energia hidrelétrica, e restrições à navegação dos rios e à pesca em águas interiores; como consequências indiretas referem-se os incêndios florestais, os problemas fitossanitários, o aumento da concentração de poluentes nos meios hídricos e consequente degradação da qualidade da água, e o agravante processo de erosão do solo. 
Figura 8: (A) Situação de extrema seca em corpos lênticos rurais no município de Paranaíba em 2014. (B) Situação de extrema seca no rio Paranaíba na divisa dos estados de MS e MG em 2014.

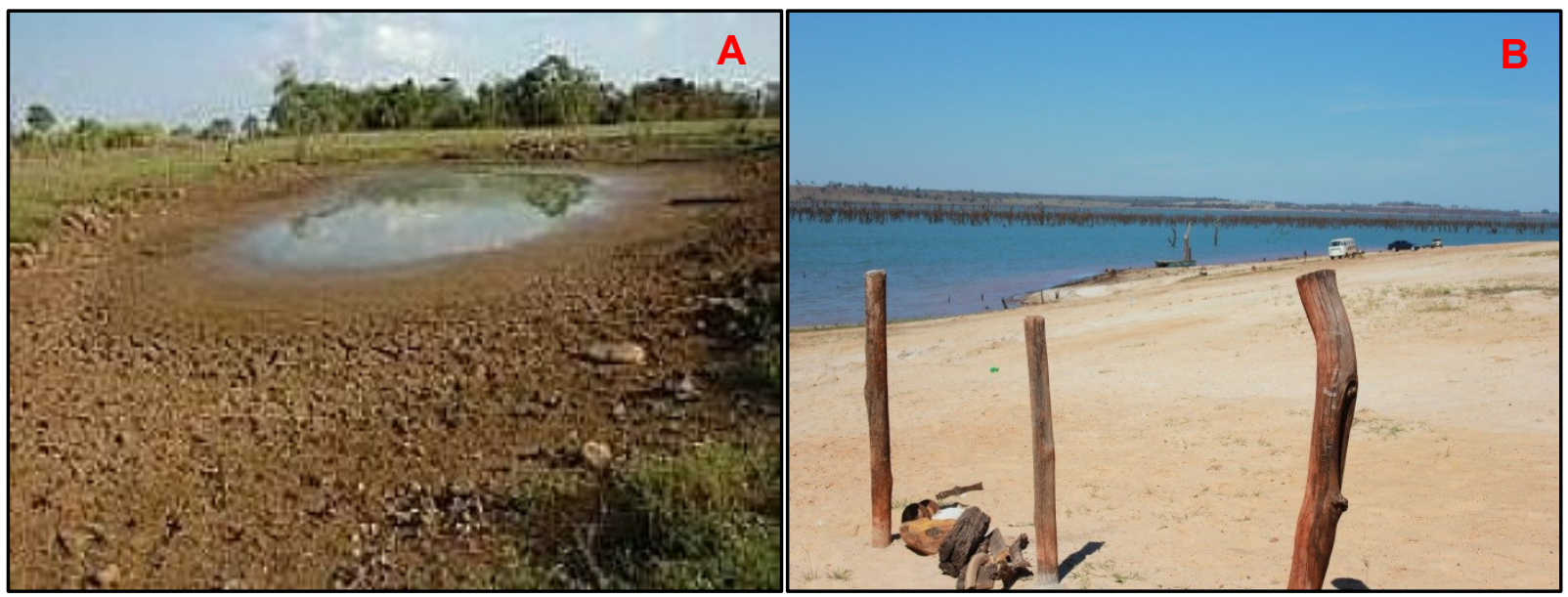

Fonte: Do autor.

Concluiu-se academicamente que ambas as ferramentas ilustrativas e estatísticas são de importante utilidade para o conhecimento do balanço hídrico pluvial e as mesmas mostram quais os possíveis eventos da variabilidade climática que exerce influência sobre a pluviometria local afetando os cursos hídricos com períodos de cheias e secas.

\section{REFERÊNCIAS}

AGÊNCIA DE DESENVOLVIMENTO AGRÁRIO E EXTENSÃO RURAL - AGRAER. Centro de Monitoramento de Tempo, do Clima e dos Recursos Hídricos de MS (CEMTEC). Disponível em: $<$ http://www.agraer.ms.gov.br/cemtec/index.php?inside $=1 \&$ tp $=3 \&$ comp $=\&$ show $=2524>$ Acesso em 25 Setembro 2014.

ARAÚJO, L. E.; MORAES NETO, J. M.; SOUSA, F. A. S. Classificação da precipitação anual e da quadra chuvosa da bacia do rio Paraíba utilizando Índice de Anomalia de Chuva (IAC). Revista Ambiente \& Água - Na Interdisciplinary Journal of Applied Science: v.4, n.3, 2009. p.93-110.

INSTITUTO BRASILEIRO DE GEOGRAFIA E ESTATÍSTICA - IBGE. Cidades. Disponível em $<$ http://www.cidades.ibge.gov.br/xtras/perfil.php?lang=\&codmun=500630\&search=mato-grosso-dosullparanaiba>. Acesso em 25 Setembro 2014.

INSTITUTO NACIONAL DE METEOROLOGIA - INMET. Normais Climatológicas do Brasil (19611990). Brasília/DF, 1992. 
MADRUGA, J.; RAO, V. B.; HADA, k. Relações entre temperatura e precipitação no Brasil. Instituto Nacional de Pesquisas Espaciais (INPE), 1999. Disponível em <http://www.cbmet.com/cbm-files/136671a0ee44a613435770f050c3e56438.pdf>. Acesso em 26 Setembro 2014.

REPELLI, C. A.; FERREIRA, N. S.; ALVES, J. M. B.; NOBRE, C. A. Índice de anomalia de precipitação para o Estado do Ceará. In: X Congresso Brasileiro de Meteorologia e VIII Congresso da FLISMET. Brasília DF. Anais; 1998.

ROOY, M. P. van, 1965. A rainfall anomaly index independent of time and space. Notos, v.14. 43p.

SANSIGOLO, C. A. Análise comparativa do desempenho dos Índices de Seca de Palmer (PDSI) e da Precipitação Normalizada (SPI) em Piracicaba, SP (1917-2001). Revista Brasileira de Meteorologia, v.19, n.1, p. 51-56, 2004.

SANTOS, M. J. J. Caracterização e Monitorização de Secas. Instituto da Água - Direcção de Serviços de Recursos Hídricos. Lisboa, 1998. 